\title{
Improvements in Fatigue in 1536 Patients with Rheumatoid Arthritis and Correlation with Other Treatment Outcomes: A Post Hoc Analysis of Three Randomized Controlled Trials of Abatacept
}

\author{
Laure Gossec · Souhila Ahdjoudj · Evo Alemao - Vibeke Strand
}

Received: December 5, 2016/ Published online: March 1, 2017

(C) The Author(s) 2017. This article is published with open access at Springerlink.com

\section{ABSTRACT}

Introduction: A post hoc analysis of three randomized controlled trials of abatacept in rheumatoid arthritis (RA) was conducted to explore the effect of abatacept on fatigue in RA and its correlation with other outcomes.

Methods: In this analysis of AGREE (early RA) and AIM and ATTAIN (established RA), changes in

Enhanced content To view enhanced content for this article go to www.medengine.com/Redeem/ DA87F06060CE17E2.

Electronic supplementary material The online version of this article (doi:10.1007/s40744-017-0054-6) contains supplementary material, which is available to authorized users.

L. Gossec

Institut Pierre Louis d'Epidémiologie et de Santé Publique, GRC-UPMC 08 (EEMOIS), Sorbonne

Universités, UPMC Université Paris 06, Paris, France

L. Gossec $(\square)$

Department of Rheumatology, Pitié Salpêtrière

Hospital, AP-HP, Paris, France

e-mail: laure.gossec@aphp.fr

\section{S. Ahdjoudj}

Bristol-Myers Squibb, Rueil-Malmaison, France

E. Alemao

Bristol-Myers Squibb, Princeton, NJ, USA

V. Strand

Stanford University School of Medicine, Palo Alto, CA, USA baseline fatigue $(0-100 \mathrm{~mm}$ scale), pain, sleep (AIM and ATTAIN only) and Disease Activity Score (DAS) 28 (C-reactive protein; CRP) were calculated at days 29, 85, and 169. Agreement between improvements $\geq$ minimum clinically important differences (MCID) in fatigue and other outcomes were evaluated using agreement statistics (kappa) in each study and at each time point. Results: Of 1536 patients (mean disease duration: 6.2 months [AGREE], 8.5 years [AIM], 12.2 years [ATTAIN]), mean (SE) decreases in fatigue from baseline to day 169 with abatacept were 28.9 (1.7), 25.3 (1.2), and 21.9 (1.6) in AGREE, AIM, and ATTAIN, respectively, with corresponding decreases of $16.0,13.7$, and 13.4 at day 29. Most patients $(67.8 \% ; 624 / 920)$ reported improvements $\geq$ MCID in fatigue with abatacept at day $169 ; 79.2 \%(671 / 847)$ and $57.8 \% \quad(388 / 671) \quad$ reported improvements $\geq$ MCID in pain and sleep, respectively; $18.9 \%$ $(158 / 836)$ were in DAS28 (CRP) remission. Agreement between improvement in fatigue and other outcomes was low (kappa range 0.30-0.51 [pain], 0.14-0.26 [sleep], and 0.02-0.12 [DAS28 (CRP) remission]).

Conclusions: Abatacept resulted in rapid improvements in fatigue and pain in patients with RA. However, low agreement between improvements in these outcomes indicates that fatigue and other outcomes including pain and sleep may represent different domains of response.

Funding: Bristol-Myers Squibb. 
Keywords: Abatacept; Biological therapy; Fatigue; Pain; Quality of life; Rheumatoid arthritis

\section{INTRODUCTION}

Rheumatoid arthritis (RA) is a chronic autoimmune disease that has a wide-ranging impact on patients' health-related quality of life [1]. Fatigue and impairment of physical and mental functioning can be direct or indirect consequences of the inflammatory response and can significantly compromise normal daily activity [1]. Patientreported outcomes (PROs) are important considerations when optimizing treatment options, and the assessment of PROs is recommended in the evaluation of therapeutic agents for RA [2]. Despite recognition of the value of measuring outcomes from the patient's perspective [3, 4], PROs often remain unaddressed [5].

Fatigue is reported by up to $80 \%$ of patients with RA [6], and severe fatigue is highly prevalent [7]. Biologic disease-modifying antirheumatic drugs (DMARDs) have been reported to reduce fatigue in RA. Treatment with abatacept, a $\mathrm{T}$ cell costimulation modulator, has also demonstrated clinically meaningful improvements in fatigue in patients with RA, but the onset of action of these effects on fatigue has not been assessed [8-11].

The causes of fatigue in RA are not completely understood. Factors other than those directly linked to inflammation and disease activity are thought to be involved [12-14]. Although a recent systematic review showed no correlation between fatigue and disease duration in RA, significant correlations were reported between fatigue and patient-reported pain and disease activity (assessed using Disease Activity Score (DAS) 28 [C-reactive protein; CRP]), with pain as the main contributor [15]. The poor sleep quality experienced by many patients with RA may also contribute to fatigue [14], and disease activity has been found to predict sleep disturbance [16]. Furthermore, multidimensional modeling has shown that disease activity leads to mood disturbance and poor sleep quality, which in turn lead to fatigue [14]. However, the factors underlying fatigue and its interrelationship with other RA symptoms needs further investigation.

This post hoc analysis examined the effect and the onset of effect of abatacept treatment on fatigue in patients with RA from three different randomized controlled trial (RCT) populations, including methotrexate (MTX)-naïve patients, MTX inadequate responders (IRs), and tumor necrosis factor- $\alpha$ (TNF)-IRs. Pain is a well-validated PRO in RA and we considered it of interest to compare treatment-related improvements in fatigue versus improvements in pain. Associations between the effect of abatacept on fatigue and pain, sleep, and DAS28 (CRP) were also explored.

\section{METHODS}

\section{Study Design}

A post hoc analysis of three abatacept RCTs was conducted to evaluate the effect of treatment on fatigue and the correlation with pain, sleep, and DAS28 (CRP) outcomes. The trials were AGREE (Abatacept study to Gauge Remission and joint damage progression in MTX-naïve patients with Early Erosive RA; NCT00122382) in early RA [17], AIM (Abatacept in Inadequate responders to Methotrexate; NCT00048568) [18], and ATTAIN (A batacept Trial in Treatment of Anti-TNF INadequate responders; NCT00048581) in established RA [19]. In AGREE, patients were either MTX naïve or had previous exposure to MTX, $\leq 10 \mathrm{mg} /$ week for $\leq 3$ weeks [17]; in AIM, patients were MTX-IRs [18] ( $\geq 15 \mathrm{mg} /$ week for $\geq 3$ months, with a stable dose for 28 days before enrollment); and in ATTAIN, patients were inadequate responders to the TNF inhibitors etanercept, infliximab, or both after $\geq 3$ months of treatment [19]. The RCTs selected included large patient populations and the same PROs at the same time points. The studies were conducted in accordance with the Declaration of Helsinki, International Conference on Harmonisation Guidelines for Good Clinical Practice, and local regulations. An Institutional Review Board or Independent Ethics Committee approved the protocol and consent form at each study site. Informed consent was obtained from all patients for being included in the study. Study designs, patient populations, and primary efficacy 
and safety results have been reported previously [17-19].

In all three trials, patients were randomized to receive either intravenous abatacept $10 \mathrm{mg} / \mathrm{kg}$ or placebo every 28 days. All patients received concomitant MTX in the AGREE and AIM trials, and patients continued concomitant DMARD medication at randomization in the ATTAIN trial.

\section{Study Assessments}

Assessments were conducted at baseline and at days 29,85 , and 169 . Fatigue and pain were assessed using visual analog scales (VAS; 0-100 mm), in which higher scores indicate worse symptoms. Sleep was assessed using the 12-item Medical Outcomes Study Sleep module (MOS-Sleep; score 0-100) in AIM and ATTAIN only. DAS28 (CRP) was evaluated at multiple time points including those when fatigue, pain, and sleep were assessed. Improvements in fatigue $\geq$ minimum clinically important differences (MCID) from baseline to day 169 were cross-tabulated with those for other outcomes and with DAS28 (CRP) remission. MCIDs were defined as pain and fatigue VAS score changes from baseline $\leq-10 \mathrm{~mm}$ [20], and sleep score change from baseline $\leq-6 \mathrm{~mm}$. DAS28 (CRP) remission was defined as DAS28 (CRP) $<2.6$.

\section{Statistical Analysis}

Data from each RCT were analyzed separately. Mean changes from baseline in fatigue and pain at each time point were determined using an analysis of covariance model, with treatment as a factor and baseline value as a covariate. Agreement between reported improvements $\geq$ MCID in fatigue with those in pain and sleep, and with attainment of DAS28 (CRP) remission were evaluated using agreement statistics (kappa) at baseline and at days 29, 85, and 169.

\section{RESULTS}

\section{Analysis Population}

Patient demographics and clinical characteristics at baseline in the original RCTs $(n=1552)$
[17-19] are shown in Table 1. Across the three trials, data for this post hoc analysis were available for a total of 1536 patients. Given the design of the trials, mean disease duration of RA for patients treated with abatacept varied from 6.2 months in AGREE to 8.5 and 12.2 years in AIM and ATTAIN, respectively.

\section{Baseline Fatigue and Other PROs}

Slightly higher mean fatigue and pain scores at baseline were observed in the patient population of ATTAIN compared with those of the patient populations of AGREE and AIM. Mean sleep scores at baseline were similar in AIM and ATTAIN, and DAS28 (CRP) scores were higher for patients in AIM than for patients in ATTAIN and AGREE (Table 1).

\section{Treatment Effect of Abatacept on Fatigue}

Changes from baseline in fatigue score were apparent by day 29 in each trial (Fig. 1a; Table 2). At day 169, improvements in fatigue $\geq$ MCID with abatacept treatment were reported by $\geq 60 \%$ of patients in AGREE, AIM, and ATTAIN (Fig. 2a). Adjusted mean treatment differences for abatacept versus placebo at day 169 were highest in the ATTAIN patient population (Table 2).

\section{Treatment Effect of Abatacept on Pain}

Changes from baseline in pain scores were more pronounced in patients with early disease (AGREE) versus those seen in patients with longer disease duration (AIM and ATTAIN; Fig. 1b); a higher proportion of patients in AGREE versus AIM or ATTAIN reported improvements in pain $\geq$ MCID with abatacept at day 169. Adjusted mean treatment differences for change from baseline in pain score for abatacept versus placebo at day 169 were highest in ATTAIN (Table 2).

\section{Association Between Changes in Fatigue and Pain with Abatacept Treatment}

Overall, most patients reporting improvements $\geq$ MCID in fatigue with abatacept treatment at 


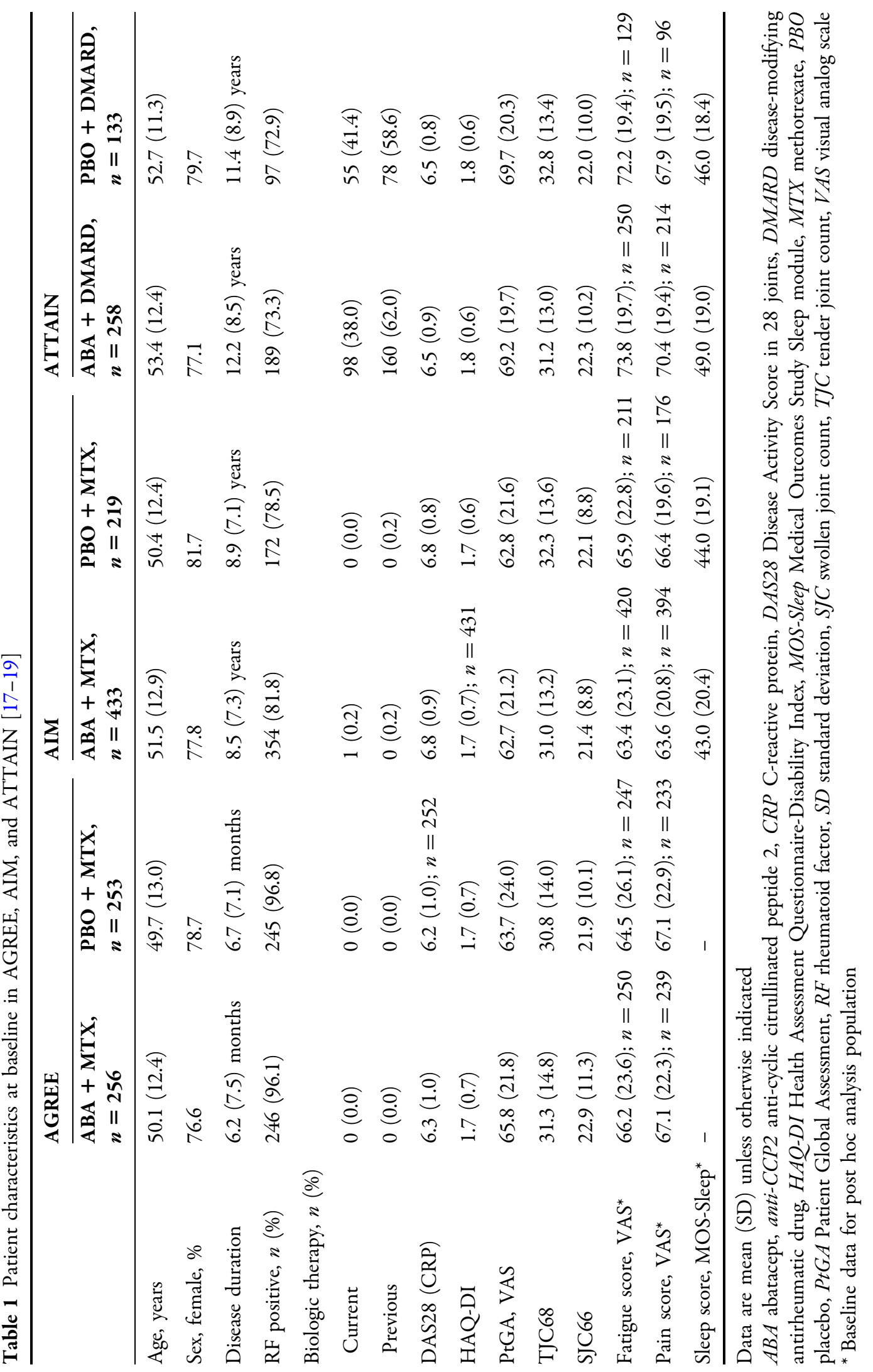


Fig. 1 Adjusted mean change from baseline in fatigue (a) and pain (b) score (VAS) over time by study. SE standard error, $V A S$ visual analog scale
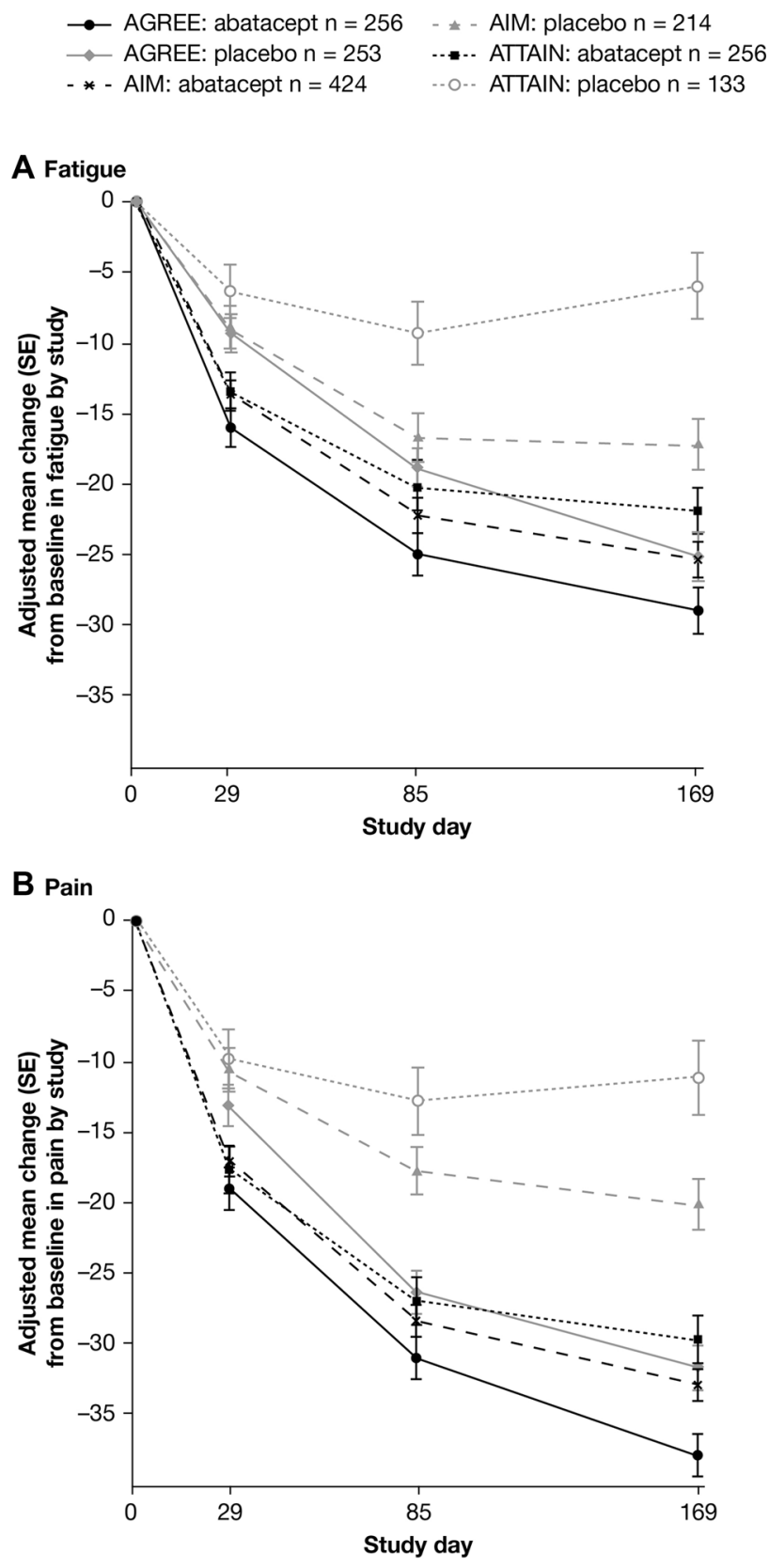

was low to moderate across the studies and time points (kappa range 0.30-0.51; Table 3).

\section{Association Between Changes in Fatigue and Other Outcomes with Abatacept Treatment}

In AIM and ATTAIN, most patients reported improvements in sleep $\geq$ MCID with abatacept and pain $>$ MCID following abatacept treatment 
Table 2 Changes from baseline fatigue and pain scores over time in AGREE, AIM, and ATTAIN

\begin{tabular}{|c|c|c|c|c|c|c|}
\hline & \multicolumn{2}{|l|}{ AGREE } & \multicolumn{2}{|l|}{ AIM } & \multicolumn{2}{|l|}{ ATTAIN } \\
\hline & $\overline{\mathrm{ABA}}+\mathbf{M T X}$ & $\mathrm{PBO}+\mathrm{MTX}$ & $\overline{\mathbf{A B A}+\mathbf{M T X}}$ & PBO + MTX & $\overline{A B A}+$ DMARD & PBO + DMARD \\
\hline $\begin{array}{l}\text { Baseline } \\
\text { fatigue } \\
\text { score, mean } \\
\text { (SD) }\end{array}$ & $66.2(23.6)$ & $64.5(26.1)$ & $63.4(23.1)$ & $65.9(22.8)$ & $73.8(19.7)$ & $72.2(19.4)$ \\
\hline \multicolumn{7}{|c|}{ Change from baseline fatigue score, adjusted mean (SE) } \\
\hline Day 29 & $-15.95(1.31)$ & $-9.29(1.32)$ & $-13.69(1.03)$ & $-8.89(1.45)$ & $-13.41(1.35)$ & $-6.27(1.88)$ \\
\hline $\begin{array}{l}\text { AMTD vs } \\
\text { PBO (95\% } \\
\text { CI) }\end{array}$ & $-6.67(-10.32$ & $,-3.01)$ & $-4.80(-8.29$ & $-1.30)$ & $-7.14(-11.69,-2$ & 2.59) \\
\hline Day 169 & $-28.85(1.65)$ & $-25.07(1.66)$ & $-25.31(1.24)$ & $-17.19(1.75)$ & $-21.89(1.63)$ & $-5.95(2.26)$ \\
\hline $\begin{array}{l}\text { AMTD vs } \\
\text { PBO (95\% } \\
\text { CI) }\end{array}$ & $-3.78(-8.37$ & $0.80)$ & $-8.13(-12.34$ & $,-3.91)$ & $-15.93(-21.42$, & $-10.45)$ \\
\hline $\begin{array}{l}\text { Baseline pain } \\
\text { score, mean } \\
\text { (SD) }\end{array}$ & $67.1(22.3)$ & $67.1(22.9)$ & $63.6(20.8)$ & $66.4(19.6)$ & $70.4(19.4)$ & $67.9(19.5)$ \\
\hline \multicolumn{7}{|c|}{ Change from baseline pain score, adjusted mean (SE) } \\
\hline Day 169 & $-37.93(1.52)$ & $-31.72(1.54)$ & $-32.89(1.19)$ & $-20.14(1.78)$ & $-29.80(1.72)$ & $-11.14(2.56)$ \\
\hline $\begin{array}{l}\text { AMTD vs } \\
\text { PBO }(95 \% \\
\text { CI })\end{array}$ & $-6.21(-10.45$ & $,-1.97)$ & $-12.75(-16.9$ & $7,-8.54)$ & $-18.66(-24.74$, & $-12.58)$ \\
\hline
\end{tabular}

Data shown are the score data available for the numbers of patients at each stage of the AGREE, AIM, and ATTAIN studies

$A B A$ abatacept, $A M T D$ adjusted mean treatment difference, DMARD disease-modifying antirheumatic drug, $M T X$ methotrexate, $P B O$ placebo, $S D$ standard deviation, $S E$ standard error

at day 169: $57.4 \%(241 / 420 ; 95 \%$ CI $52.7,62.1)$ of patients in AIM and 58.6\% (147/251; 95\% CI $52.5,64.7)$ of patients in ATTAIN. Agreement (kappa statistics) between the proportion of abatacept-treated patients with changes in fatigue and sleep $\geq$ MCID at day 169 was low in both studies at all time points (kappa range 0.14-0.26; Table 3). Cross-tabulation indicated a corresponding 46.7 and $42.3 \%$ of patients in AIM and ATTAIN, respectively, who reported improvements in fatigue $\geq$ MCID with abatacept also reported improvements in sleep $\geq$ MCID at day 169.

Agreement (kappa statistics) between treatment-related improvements in fatigue $\geq$ MCID and attainment of DAS28 (CRP) remission at day 169 was very small (0.12 [AGREE], 0.04 [AIM], and 0.06 [ATTAIN]; Table 3). Crosstabulation indicated more patients in AGREE than in AIM or ATTAIN who reported improvement in fatigue $\geq$ MCID also achieved DAS28 (CRP) remission at day 169 (26.8, 12.3, 
Fig. 2 Proportion of patients reporting improvements in fatigue (a) and pain (b) $\geq$ MCID at day 169 in AGREE, AIM, and ATTAIN. MCID for fatigue was defined as fatigue score change from baseline $\leq-10 \mathrm{~mm}$. MCID for pain was defined as pain score change from baseline $\leq-10 \mathrm{~mm}$. $A B A$ abatacept, $C I$ confidence interval, $M C I D$ minimum clinically important difference, $P B O$ placebo
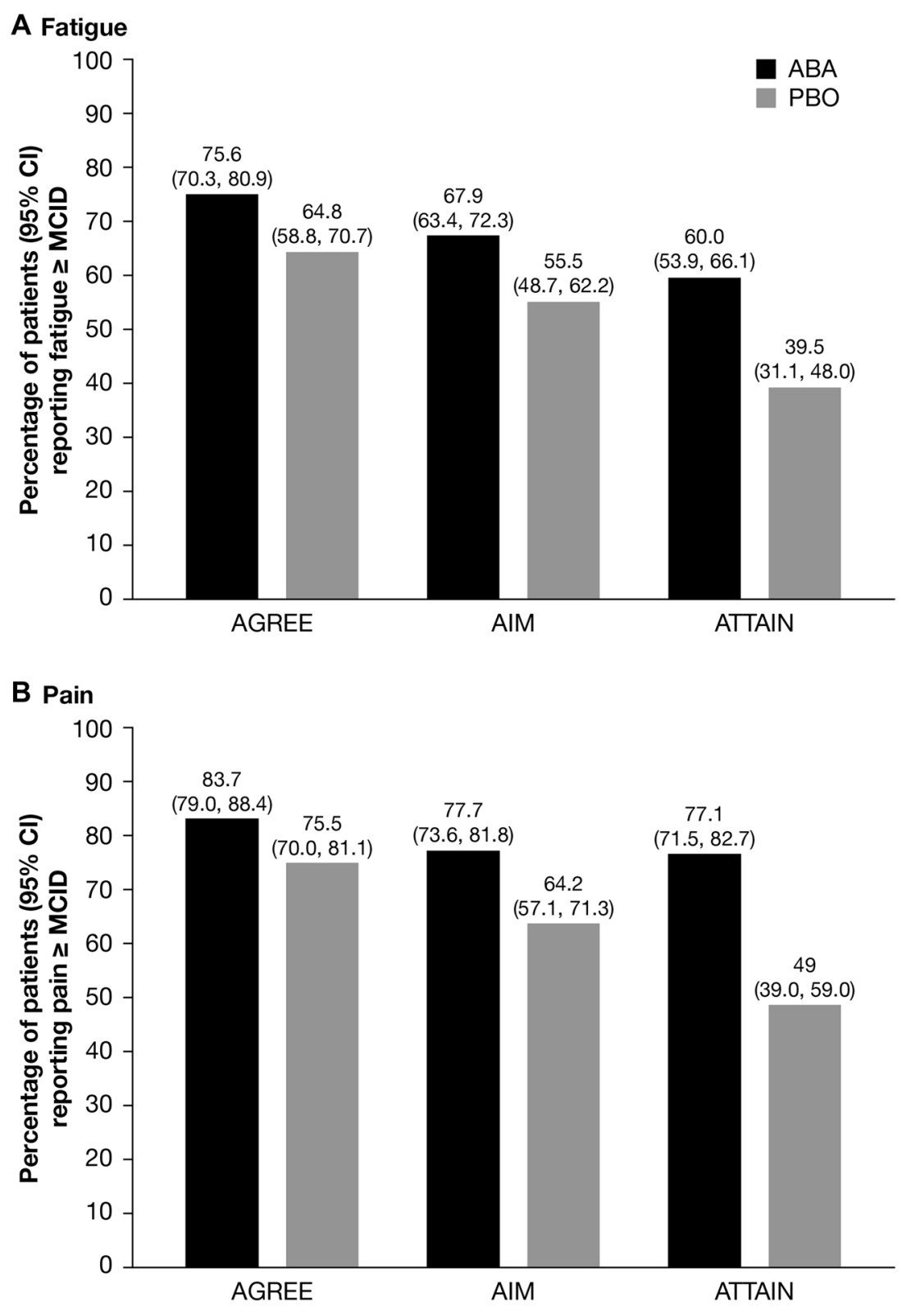

and $9.0 \%$ of patients in AGREE, AIM, and ATTAIN, respectively).

\section{DISCUSSION}

This post hoc analysis of the AGREE, AIM, and ATTAIN studies showed that treatment with abatacept led to rapid improvements in fatigue in the RA patient populations of three different RCTs. Improvements in fatigue were associated with improvements in pain, but less with improvements in sleep and attainment of DAS28 (CRP) remission.

Improvements in fatigue were reported across all three RCTs and, as expected, treatment response was higher in AGREE, in which all patients were DMARD naïve and randomized to receive either abatacept plus MTX or placebo plus MTX, than in the DMARD-experienced populations of AIM and ATTAIN. Across all three RCT populations, however, approximately 


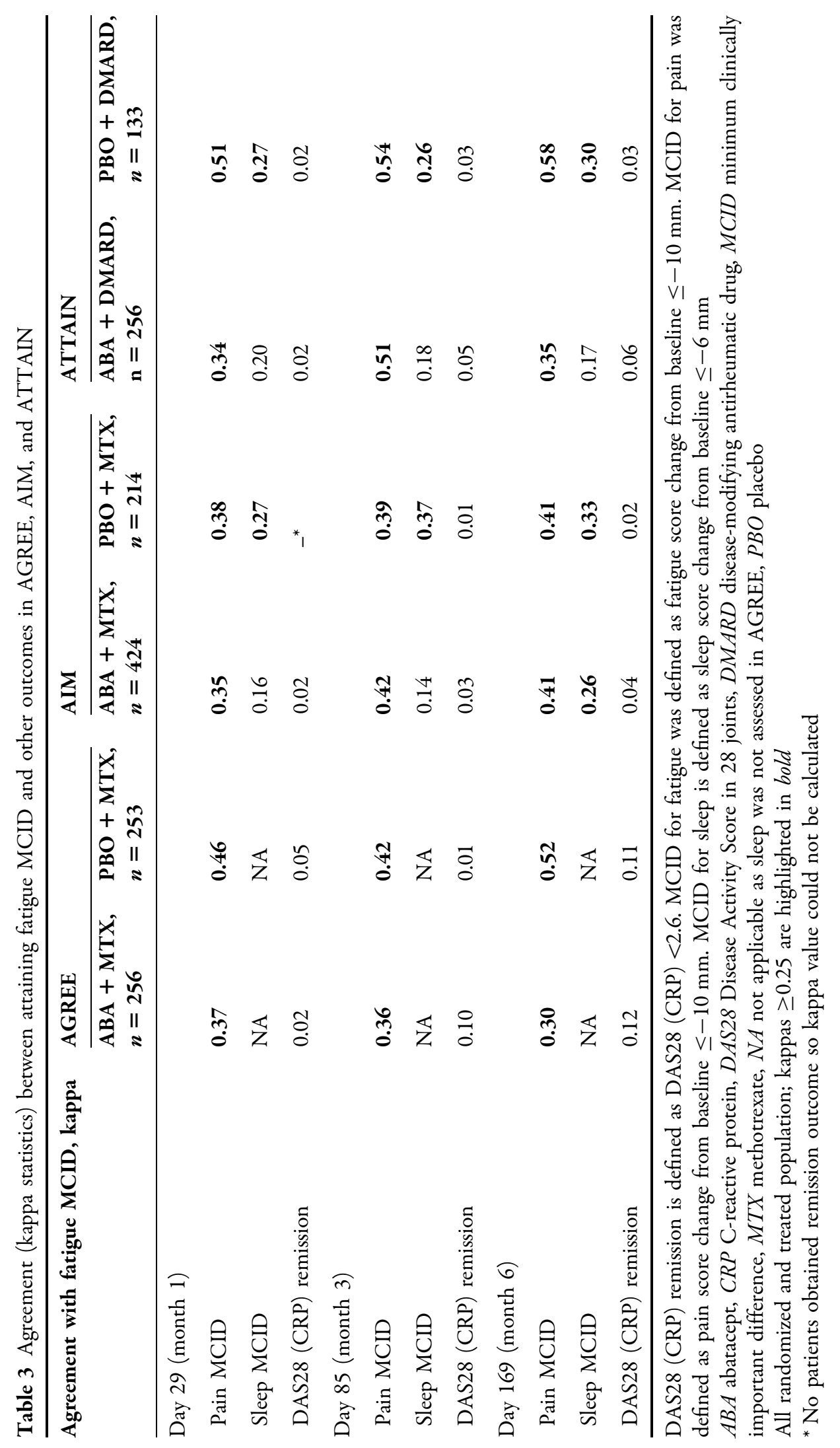


half of the treatment effect of abatacept on fatigue observed at day 169 was already apparent by day 29, indicating a rapid onset of efficacy and increasing benefit with continued treatment, at least up to 6 months, irrespective of disease duration or previous therapy.

Fatigue in RA is poorly understood and appears to be related to a multitude of factors including pain, sleep, and disease activity [13]. Fatigue and pain have been shown to be closely associated in RA, but treatment does not always impact these symptoms to the same extent $[21,22]$. In our analysis, treatment-related improvements in pain accompanied improvements in fatigue in most patients. Correlation between fatigue and pain, however, was moderate, reflecting the multifactorial nature of fatigue. A small positive association between reductions in fatigue and improvements in sleep quality was also observed. Poor sleep has been found to be significantly correlated to general and mental fatigue reported by patients with RA [23]. However, it is clear that sleep quality is not the main driver of fatigue in RA.

Fatigue experienced by patients with RA can be strongly related to disease activity as assessed using DAS28 [24], and improvements in fatigue with treatment have been shown to correlate with reductions in disease activity [22]. Examination of the relationship between fatigue and disease activity in biologic-naïve patients with RA initiating TNF-inhibitor therapy found that approximately half of the effect on fatigue associated with reduction in clinical symptoms (measured by DAS28 [CRP]) was indirect, mediated through a reduction in pain [25]. In this analysis, improvement in fatigue with abatacept treatment showed only a small association with DAS28 (CRP), possibly due to an indirect effect through improvement in health status.

These data should be interpreted within the context of the limitations of the analysis. This was a post hoc analysis of RCTs into which were recruited a high proportion of patients with poor prognosis and who were seropositive for rheumatoid factor and/or anti-cyclic citrullinated peptide. In addition, it should be noted that a numerical rating scale was used to measure fatigue in this analysis, whereas the
Functional Assessment of Chronic Illness Therapy-Fatigue (FACIT-F) [26] may be a more useful tool to explore the multidimensional nature of fatigue reported by patients with RA. An additional limitation was that sleep data were only available for two trials (AIM and ATTAIN). Of note, no longitudinal analyses were performed in the present study, which is a limitation.

\section{CONCLUSIONS}

In this post hoc analysis, abatacept treatment led to a rapid improvement in fatigue and pain in most patients with RA, irrespective of disease duration. Given the small to moderate associations observed between the effect of abatacept on fatigue and effects on pain, sleep, and disease activity, our analysis suggests the pathways underlying these outcomes often represent different domains of response in RA. An increased understanding of the complex nature and underlying causes of fatigue in RA will inform its management and potentially improve health-related quality of life for many patients.

\section{ACKNOWLEDGMENTS}

This study was sponsored by Bristol-Myers Squibb. Bristol-Myers Squibb also provided financial support for the payment of articleprocessing charges. All authors had full access to all of the data in this study and take complete responsibility for the integrity of the data and accuracy of the data analysis. All named authors meet the International Committee of Medical Journal Editors (ICMJE) criteria for authorship for this manuscript, take responsibility for the integrity of the work as a whole, and have given final approval for the version to be published. Professional medical writing and editorial assistance was provided by Linda Brown at Caudex and was funded by Bristol-Myers Squibb.

Disclosures. Laure Gossec: research grants: UCB France, Lilly France, Pfizer France, Bristol-Myers Squibb France; consulting fees: AbbVie, Bristol-Myers Squibb, Celgene, Janssen, 
Novartis, Pfizer, Roche, UCB; board member: Executive Committee of OMERACT. Souhila Ahdjoudj: employee: Bristol-Myers Squibb. Evo Alemao: shareholder and employee: Bristol-Myers Squibb. Vibeke Strand: consulting fees: AbbVie, Alder, Amgen, AstraZeneca, Bristol-Myers Squibb, Celgene, Celltrion, Corrona, Crescendo Bioscience, Genentech/Roche, GSK, Hospira, Janssen, Lilly, Pfizer, Regeneron, Sandoz, Sanofi, UCB, Vertex; board member: Executive Committee of OMERACT.

Compliance with Ethics Guidelines. The studies were conducted in accordance with the Declaration of Helsinki, International Conference on Harmonisation Guidelines for Good Clinical Practice, and local regulations. An Institutional Review Board or Independent Ethics Committee approved the protocol and consent form at each study site. Informed consent was obtained from all patients for being included in the study.

Data Availability. All data generated or analyzed during this study are included in this published article/as supplementary information files.

Open Access. This article is distributed under the terms of the Creative Commons Attribution-NonCommercial 4.0 International License (http://creativecommons.org/licenses/ by-nc/4.0/), which permits any noncommercial use, distribution, and reproduction in any medium, provided you give appropriate credit to the original author(s) and the source, provide a link to the Creative Commons license, and indicate if changes were made.

\section{REFERENCES}

1. Strand V, Khanna D. The impact of rheumatoid arthritis and treatment on patients' lives. Clin Exp Rheumatol. 2010;28:S32-40.

2. Aletaha D, Landewe R, Karonitsch T, Bathon J, Boers M, Bombardier C, et al. Reporting disease activity in clinical trials of patients with rheumatoid arthritis: EULAR/ACR collaborative recommendations. Ann Rheum Dis. 2008;67:1360-4.
3. Kirwan JR, Hewlett SE, Heiberg T, Hughes RA, Carr $\mathrm{M}$, Hehir $\mathrm{M}$, et al. Incorporating the patient perspective into outcome assessment in rheumatoid arthritis-progress at OMERACT 7. J Rheumatol. 2005;32:2250-6.

4. Gossec L, Dougados M, Dixon W. Patient-reported outcomes as end points in clinical trials in rheumatoid arthritis. RMD Open. 2015;1:e000019.

5. Taylor PC, Moore A, Vasilescu R, Alvir J, Tarallo M. A structured literature review of the burden of illness and unmet needs in patients with rheumatoid arthritis: a current perspective. Rheumatol Int. 2016;36:685-95.

6. Chauffier K, Salliot C, Berenbaum F, Sellam J. Effect of biotherapies on fatigue in rheumatoid arthritis: a systematic review of the literature and meta-analysis. Rheumatology (Oxford). 2012;51:60-8.

7. Overman CL, Kool MB, Da Silva JA, Geenen R. The prevalence of severe fatigue in rheumatic diseases: an international study. Clin Rheumatol. 2016;35:409-15.

8. Russell AS, Wallenstein GV, Li T, Martin MC, Maclean R, Blaisdell B, et al. Abatacept improves both the physical and mental health of patients with rheumatoid arthritis who have inadequate response to methotrexate treatment. Ann Rheum Dis. 2007;66:189-94.

9. Fleischmann R, Weinblatt ME, Schiff M, Khanna D, Maldonado MA, Nadkarni A, et al. Patient-reported outcomes from a 2-year head-to-head comparison of subcutaneous abatacept versus adalimumab for rheumatoid arthritis. Arthritis Care Res (Hoboken). 2016;68:907-13.

10. Wells G, Li T, Maxwell L, Maclean R, Tugwell P. Responsiveness of patient reported outcomes including fatigue, sleep quality, activity limitation, and quality of life following treatment with abatacept for rheumatoid arthritis. Ann Rheum Dis. 2008;67:260-5.

11. Westhovens R, Cole JC, Li T, Martin M, Maclean R, Lin $\mathrm{P}$, et al. Improved health-related quality of life for rheumatoid arthritis patients treated with abatacept who have inadequate response to anti-TNF therapy in a double-blind, placebo-controlled, multicentre randomized clinical trial. Rheumatology (Oxford). 2006;45:1238-46.

12. Druce KL, Jones GT, Macfarlane GJ, Basu N. Determining pathways to improvements in fatigue in rheumatoid arthritis: results from the British Society for Rheumatology Biologics Register for rheumatoid arthritis. Arthritis Rheumatol. 2015;67:2303-10. 
13. Hewlett S, Chalder T, Choy E, Cramp F, Davis B, Dures E, et al. Fatigue in rheumatoid arthritis: time for a conceptual model. Rheumatology (Oxford). 2011;50:1004-6.

14. Nicassio PM, Ormseth SR, Custodio MK, Irwin MR, Olmstead R, Weisman MH. A multidimensional model of fatigue in patients with rheumatoid arthritis. J Rheumatol. 2012;39:1807-13.

15. Madsen SG, Danneskiold-Samsoe B, Stockmarr A, Bartels EM. Correlations between fatigue and disease duration, disease activity, and pain in patients with rheumatoid arthritis: a systematic review. Scand J Rheumatol. 2016;45(4):255-61. doi:10. 3109/03009742.2015.1095943

16. Sariyildiz MA, Batmaz I, Bozkurt M, Bez Y, Cetincakmak MG, Yazmalar L, et al. Sleep quality in rheumatoid arthritis: relationship between the disease severity, depression, functional status and the quality of life. J Clin Med Res. 2014;6:44-52.

17. Westhovens R, Robles M, Ximenes AC, Nayiager S, Wollenhaupt J, Durez P, et al. Clinical efficacy and safety of abatacept in methotrexate-naive patients with early rheumatoid arthritis and poor prognostic factors. Ann Rheum Dis. 2009;68:1870-7.

18. Kremer JM, Genant HK, Moreland LW, Russell AS, Emery P, Abud-Mendoza C, et al. Effects of abatacept in patients with methotrexate-resistant active rheumatoid arthritis: a randomized trial. Ann Intern Med. 2006;144:865-76.

19. Genovese MC, Becker JC, Schiff M, Luggen M, Sherrer Y, Kremer J, et al. Abatacept for rheumatoid arthritis refractory to tumor necrosis factor alpha inhibition. N Engl J Med. 2005;353:1114-23.

20. Strand V, Boers M, Idzerda L, Kirwan JR, Kvien TK, Tugwell PS, et al. It's good to feel better but it's better to feel good and even better to feel good as soon as possible for as long as possible. Response criteria and the importance of change at OMERACT 10. J Rheumatol. 2011;38:1720-7.

21. Nikolaus S, Bode C, Taal E, van de Laar MA. Fatigue and factors related to fatigue in rheumatoid arthritis: a systematic review. Arthritis Care Res (Hoboken). 2013;65:1128-46.

22. Pollard LC, Choy EH, Gonzalez J, Khoshaba B, Scott DL. Fatigue in rheumatoid arthritis reflects pain, not disease activity. Rheumatology (Oxford). 2006;45:885-9.

23. Loppenthin K, Esbensen BA, Jennum P, Ostergaard $\mathrm{M}$, Tolver A, Thomsen $\mathrm{T}$, et al. Sleep quality and correlates of poor sleep in patients with rheumatoid arthritis. Clin Rheumatol. 2015;34:2029-39.

24. Singh H, Arya S, Talapatra P, Lather K, Mathur R, Singhania A, et al. Assessment of fatigue in rheumatoid arthritis (by functional assessment of chronic illness therapy-fatigue score) and its relation to disease activity and anemia. J Clin Rheumatol. 2014;20:87-90.

25. Druce KL, Jones GT, Macfarlane GJ, Basu N. Patients receiving anti-TNF therapies experience clinically important improvements in RA-related fatigue: results from the British Society for Rheumatology Biologics Register for Rheumatoid Arthritis. Rheumatology (Oxford). 2015;54:964-71.

26. Cella D, Yount S, Sorensen M, Chartash E, Sengupta $\mathrm{N}$, Grober J. Validation of the Functional Assessment of Chronic Illness Therapy Fatigue Scale relative to other instrumentation in patients with rheumatoid arthritis. J Rheumatol. 2005;32:811-9. 